\title{
Transanal NOTES Applications
}

\author{
Ricardo Zorron
}

Published online: 15 September 2013

(C) Springer Science + Business Media New York 2013

\begin{abstract}
In recent years, experimental studies have evolved to clinical series on natural orifice surgery, with increasing numbers published. Transanal (transrectal) NOTES using a single-port access and other platforms applied for colorectal diseases is a recent improvement, and its applications for rectal cancer and other indications are discussed. Analysis of the published reports on NOTES applied to colorectal surgery is discussed and examined with critical examination of the limitations, complications and need for new technology. New methods such as NOTES down-to-up total mesorectal resection, advanced use of transanal endoscopic microsurgery (TEM and TEO) and transanal minimally invasive surgery are described with preliminary good results and a low conversion rate. Successful reports on human transanal NOTES surgery represent a new step in minimally invasive surgery and can be applied for similar indications as laparoscopic and open surgery to improve patient care. Oncologic results have to be evaluated in further long-term studies.
\end{abstract}

Keywords Down-to-up TME - Rectal cancer - Total mesorectal excision - Colorectal surgery $\cdot$ TME $\cdot$ Natural orifice surgery $\cdot$ NOTES $\cdot$ Transcolonic $\cdot$ Minimally invasive surgery - Single-port access - LESS - TAMIS . Transanal minimally invasive surgery

\section{R. Zorron ( $\square)$}

Innovative Surgery Division, Klinikum Bremerhaven

Reinkenheide, Postbrookstrasse 66, 27574 Bremerhaven, Germany

e-mail: rzorron@gmail.com

\section{Introduction}

Recently, natural orifice surgery (NOS or NOTES) has evolved from a few experimental reports to clinical series and multicenter studies $[1 \bullet 2]$. Since the early concept from pioneers such as Kalloo et al. [3] in the US and Rao et al. [4] in India, NOTES has emerged in recent years as a promising new alternative to open and laparoscopic surgery for abdominal surgery. Providing the potential benefits of avoiding surgical incision complications such as incisional hernias, adherences, intestinal obstructions, scars and wound infections together with better cosmesis is the goal for new research in minimally invasive surgery. This evolution has led to reports in the literature of the first successful series of clinical applications of transvaginal and transgastric NOTES [5].

Transcolonic NOTES surgery was the subject of a few recent experimental studies, suggesting that the access could be an attractive option for treating colonic and abdominal diseases [6-11]. Technical obstacles to colonic access are risk of infection and leaks, safe entrance into the abdominal cavity and reliable colonic closure; these have continued to be barriers slowing transcolonic clinical applications. Despite the enthusiasm, early on the surgical community identified many issues concerning NOTES flexible techniques and soon had to migrate to the easier adaptation of one-site laparoscopy. Therefore, single-port colorectal resection is an emerging technique, with continually growing numbers of applications and acceptance worldwide.

Intrarectal surgery seems to conjoin all the advantages of transanal endoscopic microsurgery (TEM) with transanal extraction of the specimen (Natural Orifice Specimen Extraction, NOSE [12]) and transcolonic NOTES, performed with either flexible or rigid instruments. If we 
imagine that in a few years colorectal surgery will be performed predominantly through natural orifices using single ports, endoscopes, transluminal devices, and even one-arm robotics and miniature robots and cameras, it would then be possible to reach resection areas in any part of the colon once the new technology has become available.

\section{Evolution of the Concept of Transanal NOTES}

Since 2007, after IRB approval for human NOTES trials in different countries, early clinical human applications of the new method have been reported. Since Zorron et al. [13], Marescaux et al. [14], Zornig et al. [15], Bessler et al. [16] and Branco et al. [17] described successful NOTES transvaginal cholecystectomy in early 2007, other groups have followed and published their initial clinical results. Transgastric surgery was also clinically presented in meetings by Rao et al. [4] using the available endoscopic instruments, and later successful transgastric PEG rescue was described by Marks et al. [18]. Transvaginal NOTES appendectomy was first described by Palanivelu et al. [19], and Ramos et al. [20] presented a first series of transvaginal NOTES sleeve gastrectomy. Current estimation of published clinical cases reached nearly 1,200 cases [5], and two important multicenter studies were also published: the international multicenter trial IMTN study [1•] and the German Registry D-NOTES [2].

Previous clinical work regarding the use of NOS for cancer surgery was described by Hazey et al. [21] using transgastric access to evaluate pancreatic cancer and by Zorron et al. [22] using the transvaginal approach to perform liver, peritoneal, great omentum and ovarian biopsies to evaluate carcinomatosis. In the small series on NOTES surgery for cancer, natural orifice tumor implantations were not yet described, but are a matter of concern in performing oncologic resections.

Despite researchers' recent interest in the transvaginal and transgastric routes for NOTES, a small group of researchers has been dedicated to transanal and transcolonic possibilities [6-11]. Compared to the transgastric access, the transanal route offers many potential advantages by eliminating the need to retroflect the scope and steerable instruments for the upper abdomen, thus allowing more voluminous specimen extraction because of the anorectal anatomy. NOSE via transvaginal and, more recently, transrectal access [23-28] is increasingly being used to avoid larger incisions in laparoscopic surgery for large organ extraction. NOTES transvaginal sigmoidectomy assisted by minilaparoscopy was described by Lacy et al. [29], denominating the technique MA-NOS in a sigmoid cancer patient, and Burghardt et al. [30] described the first case of NOTES transvaginal right colectomy.

\section{Transcolonic NOTES in the Experimental Setting}

Experimental studies with survival and cadaver studies were performed in recent years to evaluate the transrectal NOTES access, aiming to overcome technical and anatomical issues to facilitate NOTES colorectal surgery. Working with cadavers, Whiteford et al. [31] demonstrated the feasibility of rectosigmoid resection using a rigid platform (TEM). They were able to perform rectal resection with adequate lymphadenectomy, transanal retrieval and anastomosis, and recognized the acute angle of the promontory as a true anatomic obstacle to performing rigid transrectal resections, also noting the limited reach of standard instruments.

Using a non-survival model in pigs, Sylla et al. [32] described a technique using rigid transanal resection and NOTES transgastric access as assistance to allow colonic mobilization, and Leroy et al. [33] performed a combined technique (totally NOTES) with flexible and rigid transrectal and flexible transgastric NOTES carrying out sigmoidectomies in pigs. The survival follow-up in five animals demonstrated no signs of infections and no postoperative complications.

\section{Human Transanal Down-to-Up TME}

The term down-to-up TME was coined in 2009 to describe the technique of cephalad progression of mesorectal dissection in transanal rectal resections for rectal cancer [34••, 35]. Contrary to laparoscopic total mesorectal excision, this simple difference allows for easy identification of the distal limits of the tumor and promotes an excellent clearance of the distal resection margin. Our group also reported oncologic down-to-up TME using a flexible colonoscope to enter the presacral plane and dissect the mesorectum.

The current standard of care for the treatment of rectal cancer implies a high ligation of the inferior mesenteric artery and total mesorectal resection with en bloc lymphadenectomy. The precise TME plane of dissection, described by Heald in the early 1980s, resulted in a better oncologic anatomical specimen without cell spillage, improving results and reducing the indication of abdominoperineal resections [36, 37]. From our experience with down-to-up TME, an adequate dissection with preservation of the mesorectal envelope can be achieved by flexible or rigid techniques. Transanal NOTES TME is performed in the same anatomical plane, performed in the opposite direction (from the anal to rectosigmoid junction), beginning the dissection by gaining access to the presacral plane between the presacral fascia and the mesorectum. The progression of the cephalad dissection is improved by the retropneumoperitoneum inside this avascular plane. 
The history and progress of transrectal NOTES are undoubtedly thanks to the pioneering efforts of Gerhard Buess, who described TEM in the early 1980s. It is still the standard therapy for most low rectal benign lesions [38].

\section{Down-to-Up Transanal NOTES TME using Single Port Platform}

Down-to-up TME using rigid intrarectal laparoscopy and a single-port device implies in an initial low, circular, fullthickness access to the anatomic plane of the presacral space, continuing the dissection cephalad and circumferentially [34••]. The patient is placed in the Lloyd-Davies position and receives a single dose of intravenous antibiotic prophylaxis. Transabdominal laparoscopic high ligation and left colon mobilization can be performed at the beginning or after the mesorectal resection. In the case of starting the procedure with the laparoscopic part, care must be taken not to dissect the upper rectum and posterior mesorectum because it can cause gas leakage when performing the transanal TME. The rectal lumen is disinfected by iodopovidone solution, and a disposable single-port access device is inserted transanally. The device has three channels for instrumentation, and one or two additional channels for $\mathrm{CO}_{2}$ insufflation. The pressure for intracolonic insufflation is set to $10 \mathrm{mmHg}$. Insufflators that provide continuous instead of intermittent insufflation are preferred because there will be less intraoperative lack of pressure. Usually gas leaks through the port are not a problem; the difficulty is more with leaking gas inside the small bowel. A laparoscopic camera and instruments are inserted through the port to act intraluminally (Fig. 1). The inferior limits of the tumor are identified, and the lower limit of resection is chosen at the desired line of anastomosis (Fig. 2). A purse-string suture is performed transanally at an adequate distance from the tumor margin. This unique characteristic of the down-to-up technique allows adequate visualization of the tumor margin and resection line, different from laparoscopic TME. The full-thickness circular incision reaches the plane between the presacral fascia and rectal fascia posteriorly, and the posterior wall of the vagina anteriorly, with cephalad progression. Transanal extraction of the specimen and section of the proximal colon is achieved (Fig. 3). A transverse coloplasty can be performed in the proximal colon to improve functional results, and handsewn or stapled coloanal anastomosis is performed.

\section{Flexible Down-to-Up NOTES TME}

Perirectal NOTES access (PNA) with flexible TME using a standard colonoscope implies an initial low posterior perforation of the anatomic plane between the presacral fascia and

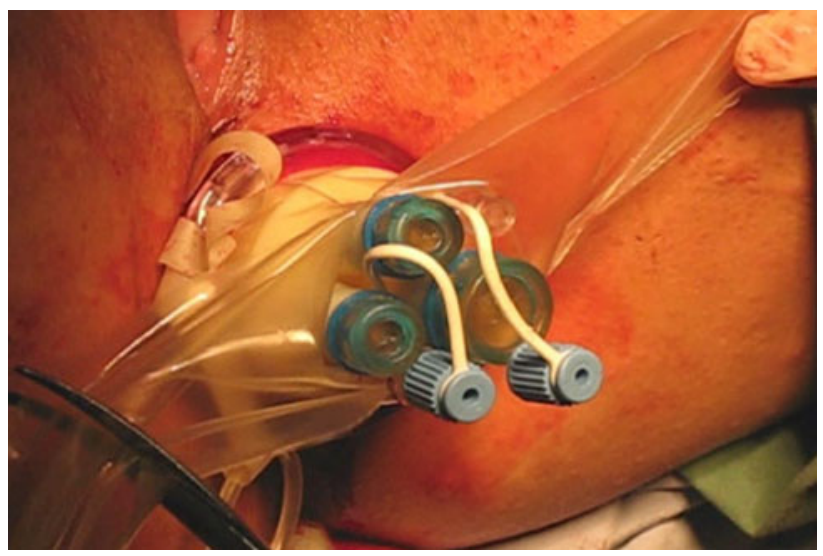

Fig. 1 Transanal insertion of a disposable single-port access device. The port is inserted transanally, and a circular intraluminal fullthickness incision allows entry into the presacral space and dissection in the anatomic oncologic plane from below. A laparoscopic camera, a 5-mm grasper and a semiflexible laparoscopic hook were inserted through the port to allow intraluminal dissection

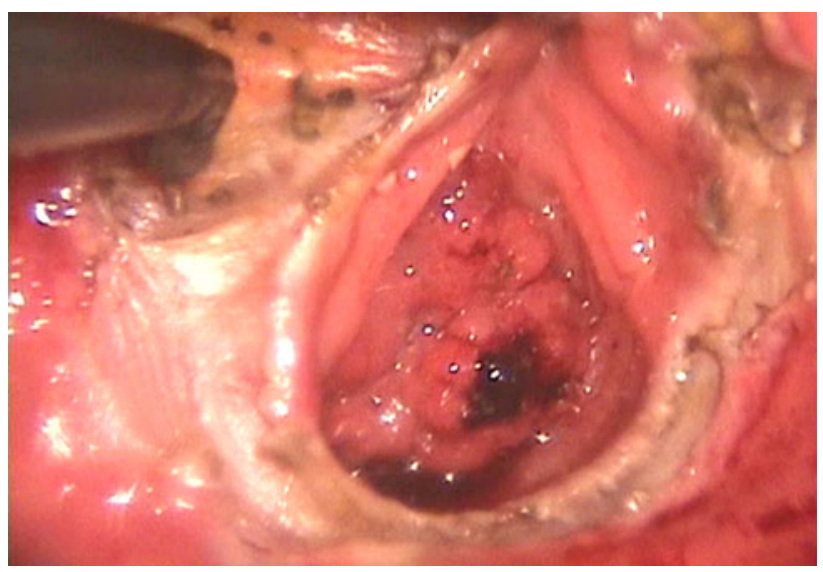

Fig. 2 The inferior limits of the tumor were identified, and the lower limit of resection was chosen. A full-thickness circular incision reached the plane between the presacral fascia and rectal fascia posteriorly, and the posterior wall of the vagina anteriorly

the fascia propria, making the dissection proximally and circumferentially (Fig. 4) [39]. Preparation of the patients is similar to the above description. The necessary equipment is an endoscopic set consisting of a single-channel videocolonoscope and laparoscopic set. An anuscope is inserted transanally, and the rectum lumen is closed by a circumferential purse-string suture. After the closure above the limit of the rectal section, the distal rectum is disinfected. The anal verge is identified, and a small posterior incision is performed exactly in the planned line of the rectal resection using monopolar cautery under direct visualization. The access orifice is tested by digital exploration, and the colonoscope is inserted directly in the perirectal retroperitoneal space. Total mesorectal resection is progressively accomplished using endoscopic monopolar scissors (Apollo Endosurgery, Austin, 


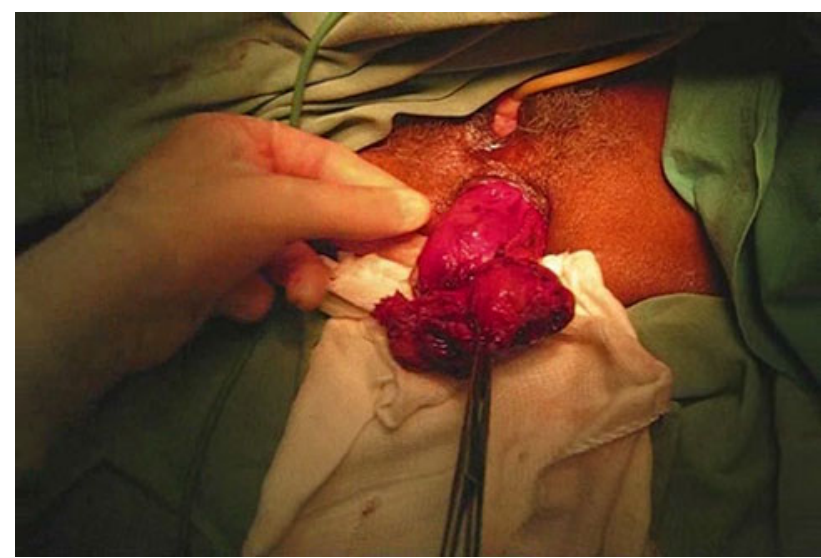

Fig. 3 Full mobilization is achieved with laparoscopic assistance, allowing transanal extraction of the specimen and section of the proximal colon

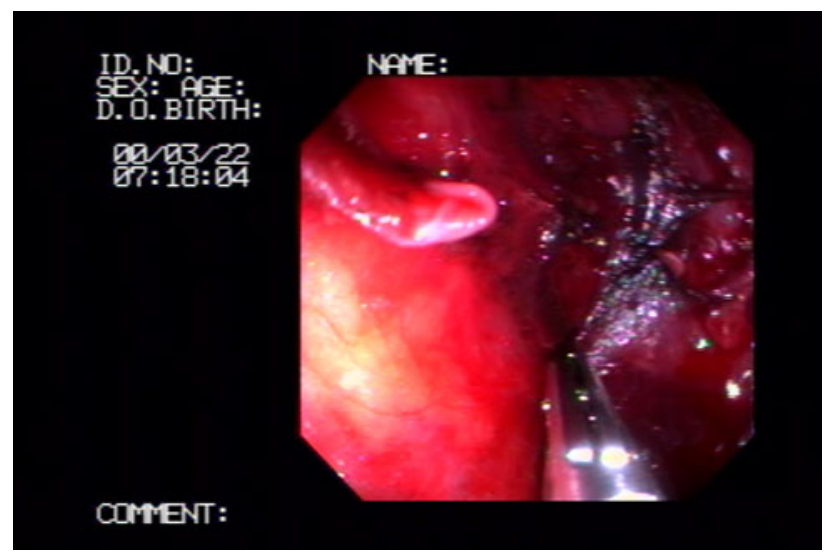

Fig. 4 Endoscopic view of flexible down-to-up TME for rectal cancer using a standard colonoscope. The endoscope is inserted directly in the presacral space, $3 \mathrm{~cm}$ above the dentate line, allowing flexible dissection in the anatomic oncologic plane from below. Total mesorectal resection is progressively accomplished using endoscopic monopolar scissors inside the ideal oncologic plane of dissection

TX) in the oncologic plane between the presacral fascia and the mesorectal fascia (Fig. 4), with posterior and anterior cephalad progression, finally reaching the peritoneal cavity. To provide high vascular ligation, a laparoscopic camera is inserted transumbilically, and a high ligature and sectioning of the inferior mesenteric artery at the level of the aorta insertion are performed using a standard three-trocar technique, also to mobilize the splenic flexure. The specimen is grasped and fully extracted transanally, and transanal stapled anastomosis is performed. Proximal loop ileostomy is performed in most cases to protect the low anastomosis.

\section{Transanal Minimally Invasive Surgery (TAMIS)}

The concept of substituting the indications for transanal endoscopic microsurgery (TEM or TEO) by means of insertion of a specially designed single-port device represents an elegant solution for the difficult learning curve for TEM. The term coined by Sergio Larach of Florida transduces formal laparoscopic surgery inside the intranal inserted single-port platform [40]. Because of the malleable design of the platforms, this may translate into a less adverse effect on anorectal function compared to TEM (which utilizes a 40-mm rigid rectoscope). In prospective studies, TEM has been associated with short-term anal dysfunction, including a reduction in anal sphincter tone and a significant decrease in maximal resting and contraction pressures for up to 6 weeks postoperatively [41, 42]. The inserted port can be removed and reintroduced at any time; furthermore, allowing insertion of conventional laparoscopic instruments (such as staplers) through an optional 12-mm port is a feature exclusive to TAMIS (transanal minimally invasive surgery) and cannot be accomplished by TEM [43••].

\section{Current Clinical Results}

Our series of 11 patients with elective surgical indications for oncologic resection for rectal cancer were submitted to down-to-up transanal NOTES TME with laparoscopic assistance [39]. The interventional team is multidisciplinary, composed of a general surgeon, a gastroenterologist-endoscopist and surgical residents. After survival studies in swine models for the previous 10 months, solving problems of spatial orientation, insufflation and instrumental development, inclusion of human series was approved by the institutional review board for transcolonic NOTES clinical trials.

Preliminary results showed good postoperative courses of the patients with few complications recorded. Surgical specimens showed adequate circumferential and distal margins, with regular numbers of lymph nodes retrieved. Operative times were long, especially in cases of flexible surgery (350-410 $\mathrm{min}$ ). There was one conversion to open surgery in a patient with a bulky tumor that could not be dissected by laparoscopic maneuvers. Transfusion was not required, and complications were recorded in two patients. One patient claimed transitory paresthesia of both feet due to intraoperative positioning; this disappeared after 10 days. One patient had a postoperative leak due to necrosis of the proximal anastomosis and required open reoperation, colostomy and drainage, and was discharged home after 11 days.

Fuchs et al. published a series of 15 patients using a hybrid technique with three trocars for benign indications [44•]. Transanal access was used to insert the staplers and anvil and to extract the specimen. There were few complications (one postoperative bleeding) and one conversion to full laparoscopy. 
Tuech et al. reported one case of transanal TME, first performing full-thickness rectal resection using a transanal technique followed by introduction of the port already in the correct plane of dissection [45•]. A second port was used transabdominally at the planned incision for protective ileostomy.

Sylla and co-workers described transanal dissection for rectal cancer in one female patient, creating the access with a regular transanal endoscopic microsurgery (TEM) device $[46 \bullet \cdot]$. The technique was performed using the principles of down-to-up dissection and produced adequate oncologic resection without complications. From the same study group, Lacy et al. [47] recently reported transanal TME for rectal cancer in a series of 20 patients. Using the GelPOINT Path Transanal Access Platform (Applied Medical, Rancho Santa Margarita, CA, USA), they obtained a mean operating time of 234 min and mean circumferential margin of $1.8 \mathrm{~cm}$. They recognized contraindications at this point for patients with preoperative $\mathrm{T} 4$, obese patients (BMI over $35 \mathrm{~kg} / \mathrm{m}^{2}$ ) and tumor recurrence.

Velthuis et al. [48] described five cases of down-to-up dissection using two SILS devices (Covidien, New Haven, $\mathrm{CT}$ ): one inserted transanally without fixation to the skin and a second transabdominally in the point chosen for the protective ileostoma. In the five patients, adequate mesorectal envelope integrity was achieved, with adequate margins and numbers of lymph nodes.

Using the adaptation of new single-port platforms for rectal surgery, bigger series are expected. Sergio Larach's group in Orlando, Florida, had over 50 cases including benign indications but also transanal TME [49••]. He called the technique TAMIS, and it currently seems to replace the earlier indications for transanal endoscopic microsurgery (TEM and TEO) (Figs. 5, 6, 7). More than 2/3 of the patients were discharged on the same day; only $6 \%$ had microscopic margin infiltration. Two recurrences were recorded $(4 \%)$ at 4 and 18 months. Advantages for the TAMIS technique are the short learning curve and the possibility to use a normal set of laparoscopic instruments.

These encouraging initial series suggest that the downto-up principle is feasible with low complication rates. Whether oncologic and postoperative results are comparable to those of current standard techniques is not yet clear, and this still has to be proven in further studies.

\section{Conclusions and Future Perspectives}

NOS, despite the enthusiasm raised and the promising potential advantages, with the exception of transoral endoscopic treatment of achalasia (peroral endoscopic myotomy, POEM [50]), has not yet shown superiority over standard surgical

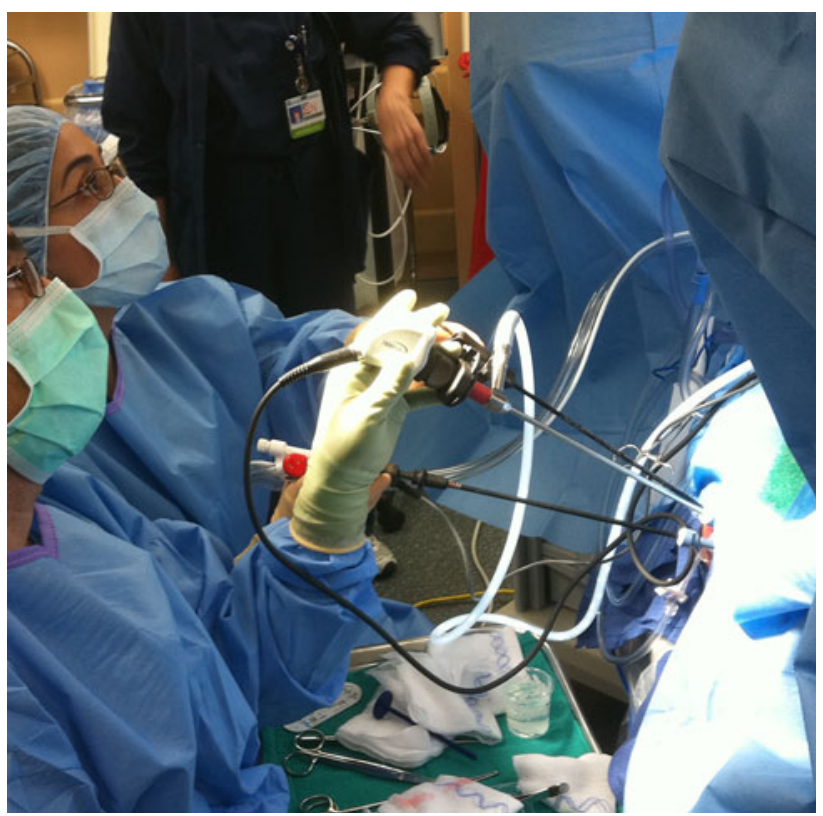

Fig. 5 TAMIS. The lesion is a pT1 adenocarcinoma $8 \mathrm{~cm}$ from the anal verge. The two-surgeon team is performing TAMIS with a 5-mm 30 lens (Maryland) and spatula cautery/suction irrigator; the patient is in candy-cane stirrups. (Courtesy of Sergio Larach and Sam Attalah, Orlando, FL)

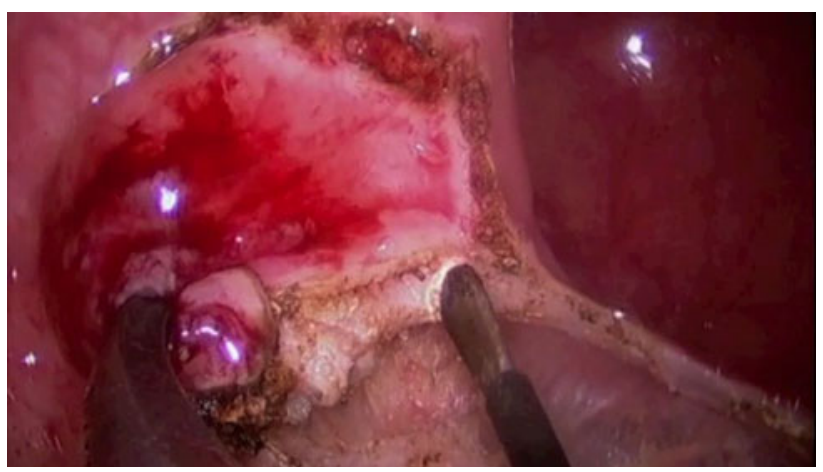

Fig. 6 TAMIS. A dedicated transanal platform is inserted with controlled insufflation and laparoscopic instruments to perform resection of a pT1 rectal carcinoma $8 \mathrm{~cm}$ from the anal verge. (Courtesy of Sergio Larach and Sam Attalah, Orlando, FL)

therapy for any medical indications [51]. Experimental and clinical studies still show that the technology needs to be developed further to expand the possibilities of the new field, improving the safety and efficiency of NOTES techniques.

NOTES applied to colorectal surgery may represent the first true application resulting in a tangible benefit for the patient. Adherence to the principles of oncologic resection is vital and opens a wide range of possibilities for future applications of transcolonic NOTES for colorectal surgery. The usual early indications for TEM are rapidly being substituted by transanal NOTES surgery in many centers 


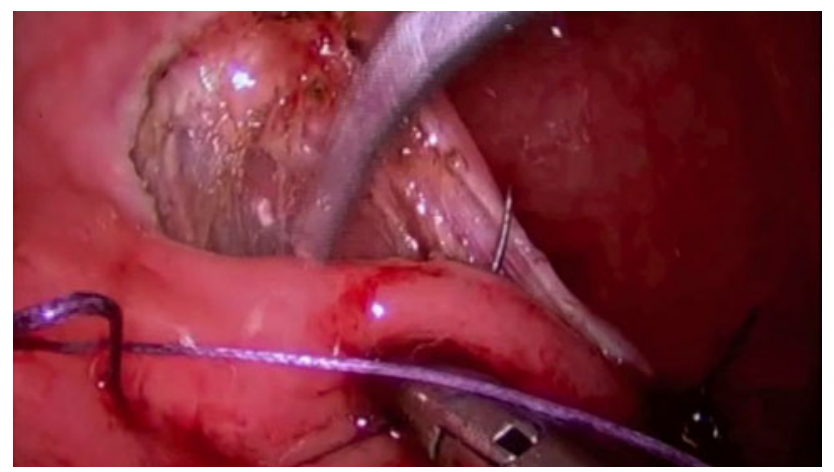

Fig. 7 TAMIS. Suturing the rectal defect transanally after achieving adequate margins. (Courtesy of Sergio Larach and Sam Attalah, Orlando, FL)

worldwide. Although advantages over existing laparoscopic and open methods cannot be distinguished in this early stage of the concept, flexible or rigid single-port transorificial performance of colorectal operations seems promising.

The preference from TAMIS over TEM may be explained by the short learning curve for the former, as the available laparoscopic instrumentarium is used, with a more ergonomic surface and ease of physician access to disposable single-port devices. The port design represents another advantage as the malleable materials of single ports are possibly less deleterious to the sphincter because the pliable design with a relatively small diameter $(3 \mathrm{~cm}$ instead of $4 \mathrm{~cm}$ for TEM) allows safe and atraumatic transanal access.

Conversion to open surgery when performing laparoscopic TME is sometimes unavoidable because of technical issues, such as encountered in cases of a narrow pelvis and bulky tumor, with resulting impaired distal dissection. Sometimes a reliable distal tumor-free margin cannot be estimated well intraoperatively for mid-rectal tumors. Before this now revolutionary concept of transanal NOTES, rectal cancer TME was invariably approached transabdominally, beginning at the proximal rectum, resulting in a top-to-bottom TME. The down-to-up principle is the opposite, starting the dissection distal to the tumor and working upwards, giving new options for difficult cases and possibly reducing the need for conversion.

\section{Compliance with Ethics Guidelines}

Conflict of Interest Ricardo Zorron declares that he has no conflict of interest.

Human and Animal Rights and Informed Consent With regard to the author's research cited in this article, all institutional and national guidelines for the care and use of laboratory animals were followed. In addition, all procedures were followed in accordance with the ethical standards of the responsible committee on human experimentation and with the Helsinki Declaration of 1975, as revised in 2000 and 2008.

\section{References}

Recently published articles of particular interest have been highlighted as:

- Of importance

•• Of major importance

1. - Zorron R, Palanivelu C, Galvão Neto MP, Ramos A, Salinas G, Burghardt J, Decarli L, Henrique Sousa L, Forgione A, Pugliese R, Branco AJ, Balashanmugan TS, Boza C, Corcione F, D'Avila Avila F, Arturo Gómez N, Galvão Ribeiro PA, Martins S, Filgueiras M, Gellert K, Wood Branco A, Kondo W, Inacio Sanseverino J, de Sousa JA, Saavedra L, Ramírez E, Campos J, Sivakumar K, Pidigu Seshiyer Rajan, Priyadarshan Anand Jategaonkar, Ranagrajan M, Parthasarathi R, Senthilnathan P, Prasad M, Cuccurullo D, Müller V. International Multicenter Trial on Clinical Natural Orifice Surgery-NOTES IMTN study: preliminary results of 362 patients. Surg Innov. 2010;17(2): 142-58. PMID: 20504792. Multicenter Study on clinical NOTES reporting results and complications, among other techniques, on NOTES for colorectal surgery.

2. Lehmann KS, Ritz JP, Wibmer A, Gellert K, Zornig C, Burghardt J, Büsing M, Runkel N, Kohlhaw K, Albrecht R, Kirchner TG, Arlt G, Mall JW, Butters M, Bulian DR, Bretschneider J, Holmer C, Buhr HJ. The German registry for natural orifice translumenal endoscopic surgery: report of the first 551 patients. Ann Surg. 2010;252(2):263-70.

3. Kalloo AN, Singh VK, Jagannath BS, Niiyama H, Hill SL, Vaughn CA, Magee CA, Kantsevoy SV. Flexible transgastric peritoneoscopy: a novel approach to diagnostic and therapeutic interventions in the peritoneal cavity. Gastrointest Endosc. 2004;60(1):287-92.

4. Rao GV, Reddy DN, Banerjee R. NOTES: human experience. Gastrointest Endosc Clin N Am. 2008;18:361-70.

5. Chukwumah C, Zorron R, Marks JM, Ponsky JL. Current status of natural orifice transluminal endoscopic surgery. Curr Probl Surg. 2010;47(8):630-68.

6. Pai RD, Fong DG, Bundga ME, Odze RD, Rattner DW, Thompson CC. Transcolonic endoscopic cholecystectomy: a NOTES survival study in a porcine model (with video). Gastrointest Endosc. 2006;64:428-34.

7. Wilhelm D, Meining A, von Delius S, Fiolka A, Can S, von Weyhern CH, Schneider A, Feussner H. An innovative, safe and sterile sigmoid access (ISSA) for NOTES. Endoscopy. 2007;39: 401-6.

8. Ryou M, Fong DG, Pai RD, Sauer J, Thompson CC. Evaluation of a novel access and closure device for NOTES applications: a transcolonic survival study in the porcine model. Gastrointest Endosc. 2008;67(6):964-9.

9. Ryou M, Thompson CC. Techniques for transanal access to the peritoneal cavity. Gastrointest Endosc Clin N Am. 2008;18: 245-60.

10. Sporn E, Bachman SL, Miedema BW, Loy TS, Calaluce R, Thaler $\mathrm{K}$. Endoscopic colotomy closure for natural orifice surgery using a $\mathrm{T}$-fastener prototype in comparison to conventional laparoscopic suture closure. Gastrointest Endosc. 2008;68(4):724-30.

11. Bachman SL, Sporn S, Furrer JL, Astudillo JA, Calaluce R, McIntosh MA, Miedema BW, Thaler K. Colonic sterilization for natural orifice translumenal endoscopic surgery (NOTES) procedures: a comparison of two decontamination protocols. Surg Endosc. 2009;23:1854-9.

12. Palanivelu C, Rangarajan M, Jategaonkar PA, Anand NV. An innovative technique for colorectal specimen retrieval: a new era 
of "natural orifice specimen extraction" (N.O.S.E). Dis Colon Rectum. 2008;51(7):1120-4.

13. Zorron R, Filgueiras M, Maggioni LC, Pombo L, Carvalho GL, Oliveira AL. NOTES transvaginal cholecystectomy: report of the first case. Surg Innov. 2007;14(4):279-83.

14. Marescaux J, Dallemagne B, Perretta S, Wattiez A, Mutter D, Coumaros D. Report of transluminal cholecystectomy in a human being. Arch Surg. 2007;142:823-6.

15. Zornig C, Emmerman A, von Waldenfels HA, Mofid H. Laparoscopic cholecystectomy without visible scar: combined transvaginal and transumbilical approach. Endoscopy. 2007;39(10):913-5.

16. Bessler M, Stevens PD, Milone L, Parikh M, Fowler D. Transvaginal laparoscopically assisted endoscopic cholecystectomy: a hybrid approach to natural orifice surgery. Gastrointest Endosc. 2007;66(6):1243-5.

17. Brancofilho AJ, Noda RW, Kondo W, Kawahara N, Rangel M, Branco AW. Initial experience with hybrid transvaginal cholecystectomy. Gastrointest Endosc. 2007;66(6):1245-8.

18. Marks JM, Ponsky JL, Pearl JP, McGee MF. PEG rescue: a practical NOTES technique. Surg Endosc. 2007;21(5):816-9.

19. Palanivelu C, Rajan PS, Rangarajan M, Parthasarathi R, Senthilnathan P, Prasad M. Transvaginal endoscopic appendectomy in humans: a unique approach to NOTES-world's first report. Surg Endosc. 2008;22(5):1343-7.

20. Ramos AC, Zundel N, Neto MG, Maalouf M. Human hybrid NOTES transvaginal sleeve gastrectomy: initial experience. Surg Obes Relat Dis. 2008;4(5):660-3.

21. Hazey JW, Narula VK, Renton DB, Reavis KM, Paul CM, Hinshaw KE, Muscarella P, Ellison EC, Melvin WS. Natural orifice transgastric endoscopic peritoneoscopy in humans: initial clinical trial. Surg Endosc. 2008;22:16-20.

22. Zorron R, Soldan M, Filgueiras M, Maggioni LC, Pombo L, Oliveira AL. NOTES transvaginal for cancer diagnostic staging: preliminary clinical application. Surg Innov. 2008;15(3):161-5.

23. Delvaux G, Devroey P, De Waele B, Willems G. Transvaginal removal of gallbladders with large stones after laparoscopic cholecystectomy. Surg Laparosc Endosc. 1993;3(4):307-9.

24. Zornig C, Emmerman A, von Waldenfels HA, Felixmuller C. Colpotomy for specimen removal in laparoscopic surgery. Chirurg. 1994;65(10):883-5.

25. Breda G, Silvestre P, Giunta A, Xausa D, Tamai A, Gherardi L. Laparoscopic nephrectomy with vaginal delivery of the intact kidney. Eur Urol. 1993;24(1):116-7.

26. Abrao MS, Sagae UE, Gonzales M, Podgaec S, Dias JA Jr. Treatment of rectosigmoid endometriosis by laparoscopically assisted vaginal rectosigmoidectomy. Int J Gynaecol Obstet. 2005;91(1):27-31.

27. Franklin M, Kelley H, Kelley M, Brestan L, Portillo G, Torres J. Transvaginal extraction of the specimen after total laparoscopic right hemicolectomy with intracorporeal anastomosis. Surg Laparosc Endosc Percutan Tech. 2008;18:294-8.

28. Akamatsu H, Omori T, Oyama T, Tori M, Ueshima S, Nakahara M, Abe T, Nishida T. Totally laparoscopic sigmoid colectomy: a simple and safe technique for intracorporeal anastomosis. Surg Endosc. 2009;23(11):2605-9.

29. Lacy AM, Delgado S, Rojas OA, Almenara R, Blasi A, Llach J. MA-NOS radical sigmoidectomy: report of a transvaginal resection in the human. Surg Endosc. 2008;22(7):1717-23.

30. Burghardt J, Federlein M, Müller V, Benhidjeb T, Elling D, Gellert K. Minimal invasive transvaginal right hemicolectomy: report of the first complex NOS (natural orifice surgery) bowels operation using a hybrid approach. Zentralbl Chir. 2008;133(6): 574-6.

31. Whiteford M, Denk EM, Swanstrom L. Feasibility of radical sigmoid colectomy performed as natural orifice translumenal endoscopic surgery (NOTES) using transanal endoscopic microsurgery. Surg Endosc. 2007;21:1870-4.
32. Sylla P, Willingham FF, Sohn DK, Gee D, Brugge WR, Rattner DW. NOTES rectosigmoid resection using transanal endoscopic microsurgery (TEM) with transgastric endoscopic assistance: a pilot study in swine. J Gastrointest Surg. 2008;12(10):1717-23.

33. Leroy J, Cahill RA, Perretta S, Forgione A, Dallemagne B, Marescaux J. Natural orifice translumenal endoscopic surgery (NOTES) applied totally to sigmoidectomy: an original technique with survival in a porcine model. Surg Endosc. 2009;23:24-30.

34. • Zorron R, CoelhoD, Flach L, Lemos FB, Moreira MS, Oliveira PS, Barbosa AM. Perirectal NOTES Access (PNA): Down-to-up total mesorectal excision for rectal cancer. Surg Innov. 2012;19(1):11-9. Clinical study of down-to-up transanal NOTES TME for rectal cancer. First report of the flexible and rigid technique for down-to-up TME.

35. Zorron R. Transcolonic NOTES-preliminary human experience: NOTES transrectal rectosigmoid resection and TME. 12th World Congress of Endoscopic Surgery, Landover, Washington, 17 April 2010.

36. Heald RJ, Ryall RD. Recurrence and survival after total mesorectal excision for rectal cancer. Lancet. 1986;1(8496):1479-82.

37. Heald RJ, Husband EM, Ryall RD. The mesorectum in rectal cancer surgery: the clue to pelvic recurrence? Br J Surg. 1982;69:613-6.

38. Buess G, Kipfmüller K, Ibald R, Heintz A, Hack D, Brausntein S, Gabbert H, Junginger T. Clinical results of transanal endoscopic microsurgery. Surg Endosc. 1988;2:245-50.

39. Zorron R. Natural orifice surgery and single port access applied to colorectal surgery: the new era of intrarectal surgery? G Chir. 2010;31(6):205-9.

40. Larach SW. Transanal endoscopic microsurgery (TEM) and transanal minimally invasive surgery (TAMIS). Cir Esp. 2012; 90(7):418-20.

41. Kennedy ML, Lubowski DZ, King DW. Transanal endoscopic microsurgery excision: is anorectal function compromised? Dis Colon Rectum. 2002;45(5):601-4.

42. Wang HS, Lin JK, Yang SH, Jiang JK, Chen WS, Lin TC. Prospective study of the functional results of transanal endoscopic microsurgery. Hepatogastroenterology. 2003;50(53):1376-80.

43. •- Albert MR, Atallah SB, deBeche-Adams TC, Izfar S, Larach SW. Transanal minimally invasive surgery: a giant step forward. Surg Endosc. 2010; 24(9): 2200-05. Denomination and technique of TAMIS-transanal minimally invasive surgery. Clinical experience and technical issues using a transanal single port.

44. - Fuchs KH, Breithaupt W, Varga G, Schulz T, Reinisch A, Josipovic N. Transanal hybrid colon resection: from laparoscopy to NOTES. Surg Endosc. 2013;27(3):746-52. NOTES solutions reducing ports in laparoscopic surgery and inventive techniques.

45. - Tuech JJ, Bridoux V, Kianifard B, Schwarz L, Tsilividis B, Micholt F. Natural orifice total mesorectal excision using transanal port and laparoscopic assistance. Eur J Surg Oncol. 2011;37:334-5. Technical aspects on transrectal TME using a single-port device for rectal cancer.

46. •• Sylla P, Rattner D, Delgado S, Lacy A. NOTES transanal rectal cancer resection using transanal endoscopic microsurgery and laparoscopic assistance. Surg Endosc. 2010;24(5):1205-10. Technical aspects of transrectal TME using a TEM device for clinical applications in rectal cancer.

47. Lacy AM, Rattner DW, Adelsdorfer C, Tasende MM, Fernández M, Delgado S, Sylla P, Martínez-Palli G. Transanal natural orifice transluminal endoscopic surgery (NOTES) rectal resection: "down-to-up" total mesorectal excision (TME) - short term outcomes in the first 20 cases. Surg Endosc. 2013;27(9):3165-72.

48. Velthuis S, van den Boezem PB, van der Peet DL, Cuesta MA, Sietses C. Feasibility study of transanal total mesorectal excision. Br J Surg. 2013;100(6):828-31.

49. ••Albert MR, Atallah SB, deBeche-Adams TC, Izfar S, Larach SW. Transanal minimally invasive surgery (TAMIS) for local 
excision of benign neoplasms and early stage rectal cancer: efficacy and outcomes in the first 50 patients. Dis Colon Rectum. 2013;56(3):301-7. Larger clinical series on TAMIS—transanal minimally invasive surgery. Includes new applications for rectal cancer and the evolution of the technique.

50. Inoue H, Minami H, Kobayashi Y, Sato Y, Kaga M, Suzuki M, Satodate H, Odaka N, Itoh H, Kudo S. Peroral endoscopic myotomy (POEM) for esophageal achalasia. Endoscopy. 2010;42(4):265-71.

51. Pasricha PJ, Krummel TM. NOTES and other emerging trends in gastrointestinal endoscopy and surgery: the change that we need and the change that is real. Am J Gastroenterol. 2009;104:2384-6.

52. Zorron R. NOTES applied to colorectal surgery. World J Gastrointest Surg. 2010;27(2):35-8. 